\title{
The Immune Checkpoint Molecule CD200 Is Associated with Tumor Grading and Metastasis in Bladder Cancer
}

\author{
PETER REXIN ${ }^{1 *}$, ALESSA TAUCHERT ${ }^{2}$, JÖRG HÄNZE ${ }^{2}$, HENDRIK HEERS ${ }^{2}$, \\ ANSGAR SCHMIDT $^{1}$, RAINER HOFMANN ${ }^{2}$ and AXEL HEGELE ${ }^{2 *}$ \\ ${ }^{1}$ Institute of Pathology, and ${ }^{2}$ Department of Urology and Pediatric Urology, \\ University Medical Center Marburg, Marburg, Germany
}

\begin{abstract}
Background: We examined the expression of CD200, a ligand of immune tolerance, in transitional cell carcinoma of the human bladder (TCC). Materials and Methods: CD200 was analyzed by immunohistochemistry (IHC) in 90 patients with suspected TCC lesions of the bladder. Expression of CD200 was exemplarily validated by quantitative reverse transcription polymerase chain reaction and western blot analysis. Results: CD200 was detectable at mRNA and protein levels in TCC homogenate and TCC cell lines (T24, UMUC3). TCC tissues showed significantly higher CD200 expression $(p<0.005)$ than normal bladder tissues. CD200 signals were also higher in metastasized compared to localized TCC $(p<0.05)$. CD200 was significantly correlated to tumor grading $(p<0.001)$ and was strongest in the subgroup with high-grade G2 TCC (vs. lowgrade G2 $p<0.05)$. Conclusion: This is the first report of CD200 expression in patients with TCC. The significant correlation between CD200 expression and tumor grading may suggest CD200 as a potential target and marker for immunotherapeutic approaches.
\end{abstract}

Despite different treatment options, bladder cancer is still associated with high morbidity and mortality rates (1). Furthermore, long-term survival is limited; e.g. in Germany, median 10-year survival rates for tumor stages overall ranged between 44 and $52 \%(1,2)$. To date, various markers have been described for prognosis and therapy monitoring but due to their low sensitivity and high costs, none of them have

*These Authors contributed equally to this study.

Correspondence to: Professor Dr. Axel Hegele, Department of Urology and Pediatric Urology, Baldingerstrasse, University Medical Center, D-35033 Marburg, Germany. E-mail: hegele@ med.uni-marburg.de

Key Words: Immunotherapy, transitional cell carcinoma, CD200, OX2. attained application in clinical routine (3-6). With a trend towards individually tailored concepts for patients with cancer, it is essential to decode the pathways of bladder cancer in order to optimize patient outcome, find relevant biomarkers, prognosticators, and specific therapeutic agents.

In the past 10 years a joint endeavor to understand the basics of cancer development bore fruit by introducing new individual therapies and prognostic indicators (7). An innovative approach in cancer treatment is inhibition of immune checkpoints, so far mainly applied to patients with renal cell cancer, and melanoma $(8,9)$. As localized bladder cancer is one of the first types of malignant tumor treated by non-specific immunotherapy with bacillus Calmette-Guérin (BCG), first described in 1976 by Morales and co-workers, particular bladder cancer subgroups may be especially susceptible to new therapeutic approaches with specific immunotherapy $(10,11)$. In 2017 , the immune checkpoint inhibitors atezolizumab, pembrolizumab and nivolumab were approved by the European Medicines Agency for the treatment of metastasized or locally advanced bladder cancer after platinum-based chemotherapy; other new substances are currently under clinical evaluation in phase III clinical trials (12-15).

CD200, a type 1a glycoprotein, is a promising biomarker, immune checkpoint and target for specific immunotherapy. CD200 is expressed in critical tissue e.g. brain and bone marrow, testis, and placenta, as well as certain leukocytes including T-and B-cells as well as macrophages $(16,17)$. The short transmembrane domain lacks a canonical signaling motif but its receptors CD200R1-R4 are found on a wide variety of bone marrow-derived cells such as dendritic cells, macrophages, and T-cells (18). Its major role seems to be the protection of immune-privileged sites and the promotion of peripheral tolerance (19). In addition, CD200 seems to play a crucial role in tissue repair, autoimmune disease, and graft rejection (20-25). There is strong evidence that tumor cells and viruses use the CD200 pathway for immune evasion (25, 26). In our study, we analyzed the expression of CD200 in human bladder cancer cell lines and in tissue of patients suffering from different stages of bladder cancer. 


\section{Materials and Methods}

Patients. The study included 90 patients with suspected TCC bladder lesions ( 60 male, 30 female; mean age $=72$ years, range $=25$ 93 years). The study was approved by the local Institutional Review Board (AZ 52/14). All patients were treated with transurethral tumor resection (TUR-BT). Resected tissue was collected in a prospective manner. Representative specimens of the formalin-fixed paraffinembedded primary tumor were selected and evaluated according to the Union international contre le cancer (UICC) classification (27). Patients with non-muscle invasive bladder cancer (NMIBC) were followed-up for tumor recurrence using a clinical database system.

RNA isolation, quantitative reverse transcription polymerase chain reaction ( $q R T-P C R)$, protein isolation and western-blot analysis. T24 (HTB-4) and UMUC3 (CRL-1749) cell lines derived from transitional cell carcinoma (ATCC, Bioresource Center, Manassas, VA, USA) were cultured in complete growth medium (RPMI 1640 supplemented with $10 \%$ fetal calf serum, PAN-Biotech, Aidenbach, Germany). Total RNA from tumor tissue or cultured cells was extracted by TriFast procedure according to the RNA isolation protocol (PEQLAB Biotechnologie, Erlangen, Germany). RNA $(0.5 \mu \mathrm{g})$ was submitted to DNAse I treatment and cDNA synthesis was performed with random hexamer primers and M-MLV reverse transcriptase in $20 \mu \mathrm{l}$ volume. cDNA solution $(1 \mu \mathrm{l})$ was submitted to SYBR green-based (Thermo Fisher Scientific, Waltham, MA, USA) qRT-PCR (IQ5, Biorad, München, Germany). Cycling conditions used were: $95^{\circ} \mathrm{C}$ for $7.5 \mathrm{~min}$ followed by 60 cycles at $95^{\circ} \mathrm{C}$ for $15 \mathrm{~s} ; 58^{\circ} \mathrm{C}$ for $30 \mathrm{~s} ; 72^{\circ} \mathrm{C}$ for $30 \mathrm{~s}$. $C D 200$ mRNA levels are displayed as Delta $\mathrm{Ct}(\Delta \mathrm{Ct})$ difference to $\beta$-actin as reference mRNA. The custom-made primer sets (Biomers, Ulm, Germany) were deduced from Genbank sequences (Acc. No. NM_001101 and NM_005944, respectively): CD200+: ACC AGC ATC CTC CAT ATC AAA GAC C, CD200-: CCG GTG ACG TTT CCA GTA CAG TAA G, amplicon length 204 bp; $\beta$-actin+: TAT CCA GGC TGT GCT ATC CCT GTA C; $\beta$-actin-TTC ATG AGG TAG TCA GTC AGG TCC C, amplicon length 168 bp.

Total protein from homogenate of one tumor tissue was prepared by TriFast procedure according to the protein isolation protocol (PEQLA Biotechnologie, Erlangen, Germany). Protein of cells was obtained according to the RIPA buffer protocol (Cell Signaling Technology Europe, Frankfurt, Germany). Protein ( $40 \mu \mathrm{g} / \mathrm{lane})$ was loaded on a gel and blotted to a nitrocellulose membrane (Biorad, Munich, Germany). After blocking, the membrane was incubated with a CD200 antibody (Catalog Number: AF2724, RD-Systems, Wiesbaden, Germany). Immunoreactions were subsequently detected by incubation with a horseradish peroxidase-coupled secondary antibody and chemiluminescence procedure.

Immunohistochemistry (IHC) staining. The specimens were cut into $3 \mu \mathrm{m}$ sections mounted on silanized positively charged slides and dried overnight. The antiserum against CD200 was generated by immunization of rabbits with recombinant human CD200 Protein (extracellular domain), following standard protocols. After serum isolation from whole blood, the antibodies were further purified by immunoaffinity-absorption with matrix-coupled antigen and validated by western blot and IHC of human placenta as best practice recommends (28). The staining procedure was performed on a DAKO Autostainer after heat treatment and antigen retrieval with Trilogy ${ }^{\mathrm{TM}}$ (Sigma-Aldrich, Taufkirchen, Germany). Dako EnVision $^{\mathrm{TM}}+$ Dual Link System-HRP (Agilent, Santa Clara, CA,
USA) was used as detection system followed by chromogen reaction and counterstaining with Mayer's hematoxylin. Staining intensity of tumor cells (cytoplasm and membrane) was determined and evaluated in a blinded fashion. For analysis the whole tumor slides were evaluated, first at low magnification and afterwards at high magnification. We assessed general staining intensity and spots of high staining intensity at low magnification. In the case of general strong CD200 expression, at least $1 \mathrm{~mm}^{2}$ of tumor was scanned at high magnification. In the case of a scattered or weak CD200 expression, the whole slide was scanned at high magnification. All staining was graded on a 4-score system as follows (see Figure 1): 0: no staining, 1: only few tumor cells stained with weak staining intensity, 2: many tumor cells stained with weak staining intensity, 3: tumor cells stained with strong staining intensity.

Statistics. All data were computerized by Microsoft Excel ${ }^{\circledR} 2013$ (Microsoft, Redmond, MA, USA) and analyzed with IBM SPSS ${ }^{\circledR}$ Statistics for Windows Version 22 (Ehningen, Germany) using the Mann-Whitney $U$-test and the Kruskal-Wallis ANOVA test. A $p$ value of less than 0.05 was considered statistically significant.

\section{Results}

CD200 was detectable at the mRNA and protein levels in TCC tissue homogenates and two human TCC cell lines (T24 and UMUC3). The levels of CD200 mRNA and protein were consistent (Figure 2).

In 20 patients (12 males, eight females, mean age $=65$ years, range $=25-90$ years), TUR-BT and subsequent evaluation of the resected tissues exhibited no signs of malignancy. These patients served as a control group.

In 70 patients (48 males, 22 females, mean age $=74$ years, range $=47-93$ years), histological examination revealed TCC: $59 \%(n=41)$ with NMIBC and $27 \%(n=19)$ with muscleinvasive (MIBC) and 14\% ( $\mathrm{n}=10)$ with metastasized disease. High-grade TCC was evident in 39 and low-grade TCC in 31 patients. The guideline-concordant treatment after primary TUR-BT comprised transurethral re-resection as well as radical surgery with urinary diversion depending on the respective tumor stage. All patient characteristics are summarized in Table I.

Results of CD200 staining of the control and the TCC groups are shown in Table II. Compared to the control group, patients with TCC had significantly higher CD200 expression $(p<0.005)$. We found no correlation between CD200 staining intensity and $\mathrm{pT}$ stage $(p=0.24)$. No difference was found between CD200 expression in patients with NMIBC $(n=41)$ and those with MIBC $(\mathrm{n}=19, p=0.13)$. In case of metastasized TCC $(n=10)$, there was a significantly higher CD200 expression compared to those with localized disease $(p \leq 0.05)$. Concerning TCC grading we found significantly elevated CD200 expression with increasing grade of malignancy (high grade $v s$. low grade, $p<0.001)$.

Comparing the subgroup of patients with high-grade G2 TCC $(n=11)$ and low-grade G2 TCC $(n=18)$, a significantly 

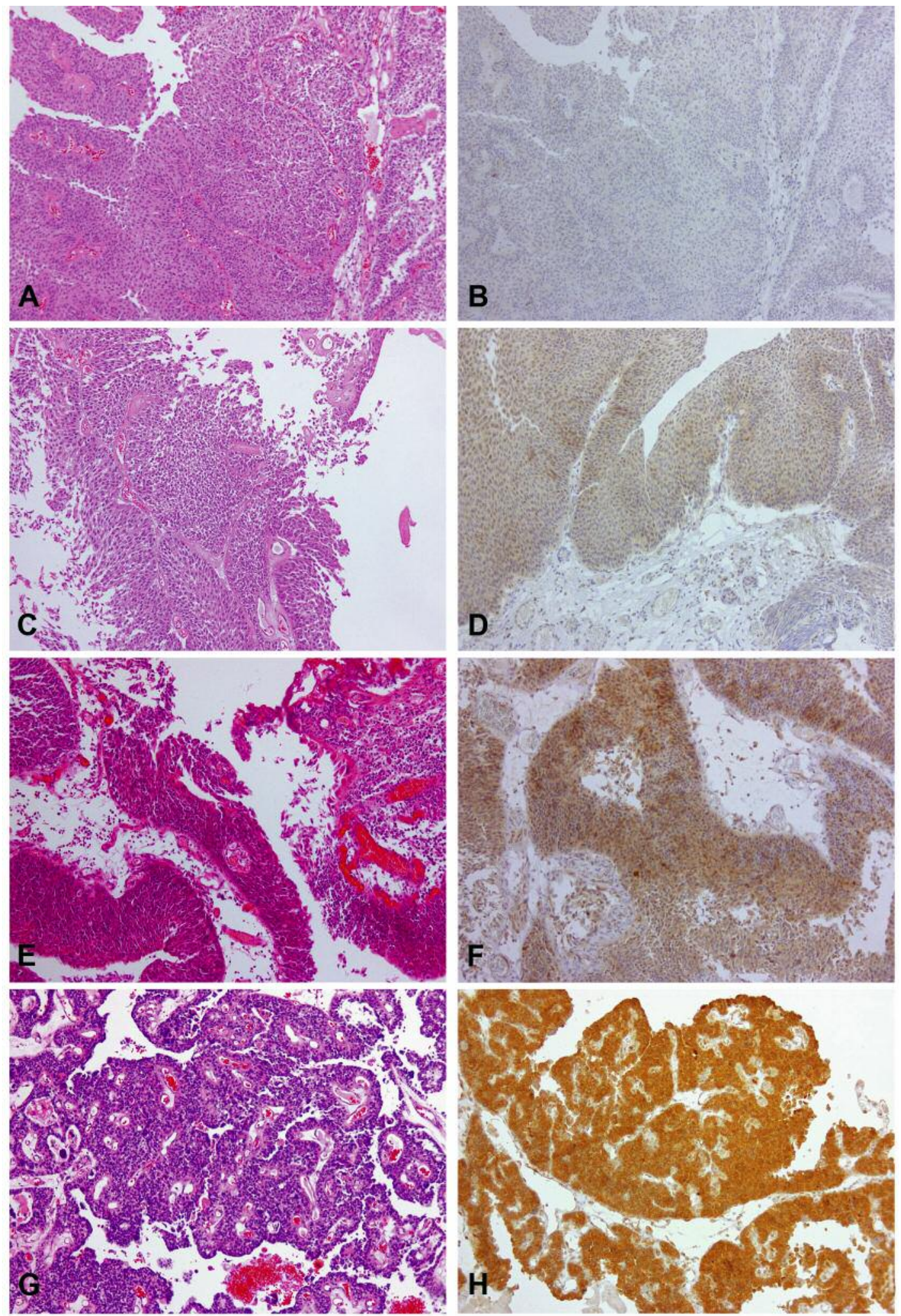

Figure 1. Examples of well- to poorly differentiated transitional cell carcinoma of the human bladder (TCC) (A, C, E, G) with corresponding immunostaining of $C D 200(B, D, F, H)$. A and B: Well-differentiated low-grade TCC and the corresponding immunohistological staining with anti$C D 200$ with score 0. $C$ and D: Intermediately differentiated low-grade TCC, with anti-CD200 score 1. E and F: Poorly differentiated high-grade $T C C$, with anti-CD200 score 2. G and H: Poorly differentiated high-grade TCC, with anti-CD200 score 3. Hematoxylin-eosin, magnification $\times 200$. 


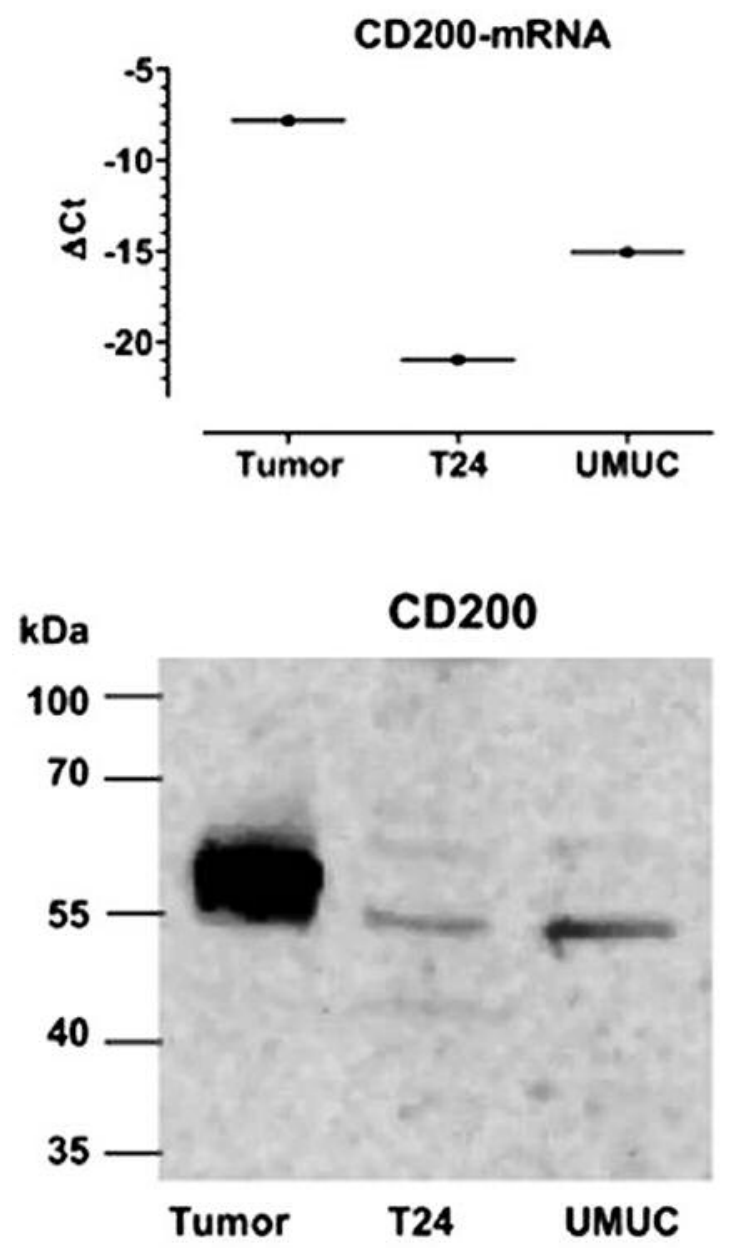

Figure 2. Exemplary analysis of CD200 expression in transitional cell carcinoma (TCC) tumor tissue (Tumor) and TCC cell lines (T24 and UMUC3). A: Quantitative analysis of CD200 mRNA by quantitative reverse transcription polymerase chain reaction relative to $\beta$-actin $m R N A(\Delta C t ;$ log-2-scale). Representative single values per sample are displayed. B: Immunodetection of CD200 by western blot analysis. The molecular weight of protein marker is indicated $(k D a)$.

stronger CD200 expression was observed in high grade G2 TCC $(p<0.05$, see Table III).

The recurrence rate for patients with NMIBC (median follow-u $p=18.5$ months, range $2-60=$ months) was $24 \%$ $(\mathrm{n}=10)$. Statistical analysis showed no correlation between TCC recurrence in NMIBC and primary CD200 expression $(p=0.73)$.

\section{Discussion}

TCC is a frequently diagnosed cancer. Due to high morbidity as well as mortality rates with limited overall survival, there is a need for novel prognostic factors and new therapeutic approaches $(1,2,6)$. Specific immunotherapy seems to be a
Table I. Patient characteristics.

\begin{tabular}{|c|c|c|c|}
\hline & & TCC & Controls \\
\hline Number & & 70 & 20 \\
\hline Age, years & Mean & 74.4 & 65 \\
\hline Gender, $\mathrm{n}$ & Male:female & $48: 22$ & $12: 8$ \\
\hline \multirow[t]{6}{*}{ pT Stage ${ }^{1}, \mathrm{n}(\%)$} & pTa & $30(42.9 \%)$ & \\
\hline & pT1 & $10(14.3 \%)$ & \\
\hline & pT2 & $12(17.1 \%)$ & \\
\hline & pT3 & $4(5.7 \%)$ & \\
\hline & pT4 & $4(5.7 \%)$ & \\
\hline & mTCC & $10(14.3 \%)$ & \\
\hline \multirow{2}{*}{ Grade $^{2}, \mathrm{n}(\%)$} & Low & $39(44.3 \%)$ & \\
\hline & High & $31(55.7 \%)$ & \\
\hline \multicolumn{4}{|l|}{ mTCC } \\
\hline Age & Mean & 73.8 & \\
\hline Gender, $\mathrm{n}$ & Male:female & $4: 6$ & \\
\hline Grade, n (\%) & Low/high & $6(100 \%) / 0$ & \\
\hline
\end{tabular}

mTCC: Metastatic transitional cell carcinoma. ${ }^{1}$ Stage in accordance to Union for International Cancer Control (UICC) (27). ${ }^{2}$ Grade in accordance to World Health Organization classification of tumours 2016.

Table II. CD200 immuno-histochemistry (IHC) staining score according to patient group.

\begin{tabular}{lllll}
\hline & $\begin{array}{l}\text { IHC 0 } \\
(\mathrm{n}=20)\end{array}$ & $\begin{array}{l}\text { IHC 1 } \\
(\mathrm{n}=24)\end{array}$ & $\begin{array}{l}\text { IHC 2 } \\
(\mathrm{n}=26)\end{array}$ & $\begin{array}{l}\text { IHC 3 } \\
(\mathrm{n}=20)\end{array}$ \\
\hline TCC $(\mathrm{n}=70)$ & $11.7 \%$ & $28.3 \%$ & $33.3 \%$ & $\begin{array}{l}26.7 \% \\
\text { Control }(\mathrm{n}=20)\end{array}$ \\
$55 \%$ & $20 \%$ & $15 \%$ & $10 \%$ \\
\hline
\end{tabular}

TCC: Transitional cell carcinoma.

Table III. CD200 immuno-histochemistry (IHC) staining score according to grade of G2 transitional cell carcinoma (TCC). CD200 staining intensity was significantly stronger in high-grade G2 TCC compared to low-grade G2 TCC ( $p<0.05)$.

\begin{tabular}{lcccc}
\hline G2 & $\begin{array}{c}\text { IHC 0 } \\
(\mathrm{n}=2)\end{array}$ & $\begin{array}{c}\text { IHC 1 } \\
(\mathrm{n}=9)\end{array}$ & $\begin{array}{c}\text { IHC 2 } \\
(\mathrm{n}=11)\end{array}$ & $\begin{array}{c}\text { IHC 3 } \\
(\mathrm{n}=7)\end{array}$ \\
\hline Low grade & $11.1 \%$ & $38.9 \%$ & $38.9 \%$ & $11.1 \%$ \\
High grade & $0 \%$ & $18.2 \%$ & $36.4 \%$ & $45.4 \%$ \\
\hline
\end{tabular}

promising approach for optimizing the outcome in TCC but the understanding of different pathway factors, their location and interaction, as well as the translation into the clinical setting is still at the beginning $(15,29)$. CD200 is a type 1a membrane glycoprotein capable of modulating the immune system via its inhibitory receptor CD200R that is expressed on both myeloid and lymphoid cells. After their interaction, immune response is negatively regulated by suppression of 
T-cell response. Thus, CD200 and its receptor represent promising targets to improve therapy in immune-mediated as well as oncological diseases (30-33).

Here, to our knowledge for the first time, we described CD200 expression both in human TCC cell lines and in TCC tissue showing higher levels in human TCC tissue. CD200 expression in TCC tissue was significantly higher compared to benign bladder tissue. Moreover, in our cohort we observed a highly significant correlation between CD200 expression and grade of malignancy. We found no correlation with common clinical prognosticators such as pT stage, recurrence rate, or subgroups (NMIBC and MIBC), although metastatic TCC showed the highest CD200 expression levels.

Nevertheless, our initial data provide a strong indication for a putative role of CD200 in the immune-evasion of bladder cancer as already noted in other malignancies. Gorczynski et al. demonstrated CD200-dependent immuneevasion in a transgenic mouse model of breast cancer (3437). Furthermore, in acute lymphocytic leukemia (AML) cell lines and in patients with chronic lymphocytic leukemia, immunomodulation was shown via CD200 signaling at the tumor cell level $(19,38)$.

It is yet unclear to what extent CD200 and its receptor CD200R may be used as a therapeutic target to affect the immune system towards antitumor response. This warrants further investigation. First in vivo and in vitro studies on CD200 blockage are on the way. First experimental data obtained from AML and breast cancer models are promising. Based on our findings, it seems worthwhile to further elucidate the role of CD200 in TCC. There is evidence that targeting the CD200-CD200R interaction, combined with chemotherapy or other immune checkpoint inhibitors, can be of therapeutic benefit in different oncological and non-oncological diseases (30). Furthermore, a clinical trial with the humanized monoclonal antibody to CD200, samalizumab, completed in 2010, showed good tolerability, dose-dependent effects on tumor growth and antitumor immune response (39). The results of an ongoing study for samalizumab in patients with advanced cancer is currently recruiting and the results are eagerly anticipated (40).

\section{Conclusion}

For the first time, CD200 expression at RNA and protein levels in different TCC cell lines and in TCC tissue were demonstrated. Immunohistochemical analyses of a clinical cohort of patients with TCC revealed CD200 expression in a wide subset of human bladder cancer with pronounced staining in poorly differentiated tumors. In particular, CD200 correlated with tumor grading and was elevated in metastatic TCC. CD200 staining was not associated with tumor recurrence or tumor stage.

\section{Acknowledgements}

The Authors thank Viktoria Wischmann for her excellent technical assistance.

\section{References}

1 Antoni S, Ferlay J, Soerjomataram I, Znaor A, Jemal A and Bray F: Bladder cancer incidence and mortality: a global overview and recent trends. Eur Urol 71: 96-108, 2017.

2 https://www.krebsdaten.de/Krebs/DE/Content/Krebsarten/ Nierenkrebs/nierenkrebs.html, Accessed 20 February 2018.

3 Schmitz-Dräger C, Bonberg N, Pesch B, Todenhöfer T, Sahin S, Behrens $\mathrm{T}$, Brüning $\mathrm{T}$ and Schmitz-Dräger BJ: Replacing cystoscopy by urine markers in the follow-up of patients with low-risk non-muscle-invasive bladder cancer? An International Bladder Cancer Network project. Urol Oncol 34: 452-459, 2016.

4 Hegele A, Mecklenburg V, Varga Z, Olbert P, Hofmann R and Barth P: CA19.9 and CEA in transitional cell carcinoma of the bladder: serological and immunohistochemical findings. Anticancer Res 30: 5195-5200, 2010.

5 Batsi O, Giannopoulou I, Nesseris I, Valavanis C, Gakiopoulou $\mathrm{H}$, Patsouris ES, Arapandoni-Dadioti $\mathrm{P}$ and Lazaris AC: Immunohistochemical evaluation of CXCL12-CXCR4 axis and VEGFR3 expression in primary urothelial cancer and its recurrence. Anticancer Res 34: 3537-3542, 2014.

$6 \mathrm{http} / / /$ leitlinienprogramm-onkologie.de/Harnblasenkarzinom. 92.0.html, Accessed 20 February 2018.

7 Hanahan D and Weinberg RA: Hallmarks of cancer: the next generation. Cell 144: 646-674, 2011.

8 Tang T, Eldabaje R and Yang L: Current status of biological therapies for the treatment of metastatic melanoma. Anticancer Res 36: 3229-3241, 2016.

9 Carlo MI, Voss MH and Motzer RJ: Checkpoint inhibitors and other novel immunotherapies for advanced renal cell carcinoma. Nat Rev Urol 13: 420-431, 2016.

10 Morales A, Eidinger D and Bruce AW: Intracavitary Bacillus Calmette-Guerin in the treatment of superficial bladder tumors. J Urol 116: 180-183, 1976.

11 Özdemir BC, Siefker-Radtke AO, Campbell MT and Subudhi SK: Current and future applications of novel immunotherapies in urological oncology: A critical review of the literature. Eur Urol Focus pii: S2405-4569, 2017.

12 Rosenberg JE, Hoffman-Censits J, Powles T, van der Heijden MS, Balar AV, Necchi A, Dawson N, O'Donnell PH, Balmanoukian A, Loriot Y, Srinivas S, Retz MM, Grivas P, Joseph RW, Galsky MD, Fleming MT, Petrylak DP, Perez-Gracia JL, Burris HA, Castellano D, Canil C, Bellmunt J, Bajorin D, Nickles D, Bourgon R, Frampton GM, Cui N, Mariathasan S, Abidoye O, Fine GD and Dreicer R: Atezolizumab in patients with locally advanced and metastatic urothelial carcinoma who have progressed following treatment with platinum-based chemotherapy: a single-arm, multicentre, phase 2 trial. Lancet 387: 1909-1920, 2016.

13 Sharma P, Callahan MK, Bono P, Kim J, Spiliopoulou P, Calvo E, Pillai RN, Ott PA, de Braud F, Morse M, Le DT, Jaeger D, Chan E, Harbison C, Lin CS, Tschaika M, Azrilevich A and Rosenberg JE: Nivolumab monotherapy in recurrent metastatic urothelial carcinoma (CheckMate 032): a multicentre, openlabel, two-stage, multi-arm, phase 1/2 trial. Lancet Oncol 17: 1590-1598, 2016. 
14 Bellmunt J, de Wit R, Vaughn DJ, Fradet Y, Lee JL, Fong L, Vogelzang NJ, Climent MA, Petrylak DP, Choueiri TK, Necchi A, Gerritsen W, Gurney H, Quinn DI, Culine S, Sternberg CN, Mai Y, Poehlein CH, Perini RF and Bajorin DF; KEYNOTE-045 Investigators: Pembrolizumab as second-line therapy for advanced urothelial carcinoma. N Engl J Med 376: 1015-1026, 2017.

15 Farina MS, Lundgren KT and Bellmunt J: Immunotherapy in Urothelial Cancer: Recent Results and Future Perspectives. Drugs 77: 1077-1089, 2017.

16 Wright GJ, Jones M, Puklavec MJ, Brown MH and Barclay AN: The unusual distribution of the neuronal/lymphoid cell surface CD200 (OX2) glycoprotein is conserved in humans. Immunology 102: 173-179, 2001

17 Gorczynski RM: CD200 and its receptors as targets for immunoregulation. Curr Opin Investig Drugs 6:483-488, 2005.

18 Barclay AN, Wright GJ, Brooke G and Brown MH: CD200 and membrane protein interactions in the control of myeloid cells Trends Immunol 23: 285-290, 2002.

19 Coles SJ, Gilmour MN, Reid R, Knapper S, Burnett AK, Man $\mathrm{S}$, Tonks A and Darley RL: The immunosuppressive ligands PDL1 and CD200 are linked in AML T-cell immunosuppression: identification of a new immunotherapeutic synapse. Leukemia 29: 1952-1954, 2015

20 Herold S, Mayer K and Lohmeyer J: Acute lung injury: how macrophages orchestrate resolution of inflammation and tissue repair. Front Immunol 2: 65, 2011.

21 Ren Y, Yang B, Yin Y, Leng X, Jiang Y, Zhang L, Li Y, Li X, Zhang $\mathrm{F}$, $\mathrm{He} \mathrm{W}$, Zhang $\mathrm{X}$ and Cao $\mathrm{X}$ : Aberrant CD200/CD200R1 expression and its potential role in Th17 cell differentiation, chemotaxis and osteoclastogenesis in rheumatoid arthritis. Rheumatology 54: 712-721, 2015.

22 Prodeus A, Cydzik M, Abdul-Wahid A, Huang E, Khatri I, Gorczynski R Gariepy J: Agonistic CD200R1 DNA aptamers are potent immunosuppressants that prolong allogeneic skin graft survival. Mol Ther Nucleic Acids 3: e190, 2014.

23 Gao S, Hao B, Yang XF and Chen WQ: Decreased CD200R expression on monocyte-derived macrophages correlates with Th17/Treg imbalance and disease activity in rheumatoid arthritis patients. Inflamm Res 63: 441-450, 2014.

24 Akman-Karakas A, Yalcin AD, Koc S, Gumuslu S, Senol YY, Ozkesici B, Genc GE, Ergun E, Ongut G, Yilmaz E, Uzun S and Alpsoy E: There might be a role for CD200 in the pathogenesis of autoimmune and inflammatory skin disorders. Med Sci Monit 19: 888-891, 2013 .

25 Chakera A, Bennett SC, Morteau O, Bowness P, Luqmani RA and Cornall RJ: The phenotype of circulating follicular-helper T cells in patients with rheumatoid arthritis defines CD200 as a potential therapeutic target. Clin Dev Immunol 2012: 948218, 2012.

26 Cortez M, Huynh C, Fernandes MC, Kennedy KA, Aderem A and Andrews NW: Leishmania promotes its own virulence by inducing expression of the host immune inhibitory ligand CD200. Cell Host Microbe 9: 463-471, 2011.

27 Wittekind Ch, Meyer HJ and Bootz F: TNM Klassifikation maligner Tumoren. Springer-Verlag, 2002.
28 Bordeaux J, Welsh A, Agarwal S, Killiam E, Baquero M, Hanna J, Anagnostou V and Rimm D: Antibody validation. Biotechniques 48: 197-209, 2010.

29 Gupta S, Gill D, Poole A and Agarwal N: Systemic immunotherapy for urothelial cancer: current trends and future directions. Cancers 9: pii:E15, 2017.

30 Vaine CA and Soberman RJ: The CD200-CD200R1 inhibitory signaling pathway: immune regulation and host-pathogen interactions. Adv Immunol 21: 191-211, 2014.

31 Wang CY, Hsieh YT, Fang KM, Yang CS and Tzeng SF: Reduction of CD200 expresseion in glioma cells enhances microglia activation and tumor growth. J Neurosci Res 94: 14601471,2016

32 Kojima T, Tsuchiya K, Ikemizu S, Yoshikawa S, Yamanishi Y, Watanabe M and Karasuyama H: Novel CD200 homologues iSEC1 und iSEC2 are gastrointestinal secretory cell-specific ligands of inhibitory receptor CD200R. Sci Rep 6: 36457, 2016.

33 Fraser SD, Sadofsky LR, Kaye PM and Hart SP: Reduced expression of monocyte CD200R is associated with enhaced proinflammatory cytokine production in sarcoidosis. Sci Rep 6: 38689, 2016.

34 Podnos A, Clark DA, Erin N, Yu K and Gorczynski RM: Further evidence for a role of tumor CD200 expression in breast cancer metastasis: decreased metastasis in CD200RKO mice or using CD200-silenced EMT6. Breast Cancer Res Treat 136: 117-127, 2012.

35 Gorczynski RM, Chen Z, Khatri I, Podnos A and Yu K: Cure of metastatic growth of EMT6 tumor cells in mice following manipulation of CD200:CD200R signaling. Breast Cancer Res Treat 142: 271-282, 2013

36 Gorczynski RM, Chen Z, Erin N, Khatri I and Podnos A: Comparison of immunity in mice cured of primary/metastatic growth of EMT6 or 4THM breast cancer by chemotherapy or immunotherapy. PLoS One 9: e113597, 2014.

37 Curry A, Khatri I, Kos O, Zhu F and Gorczynski R: Importance of $\mathrm{Cd} 200$ expression by tumor or host cells to regulation of immunotherapy in a mouse breast cancer model. PLoS One 12: e0171586, 2017.

38 Poh SL and Linn YC: Immune checkpoint inhibitors enhance cytotoxicity of cytokine-induced killer cells against human myeloid leukaemic blasts. Cancer Immunol Immunother 65: 525-536, 2016.

39 Mahadevan D, Lanasa M, Whelden M, Faas S, Ulery T, Kukreja A, Li L, Bedrosian C and Heffner T: Study of a humanized antiCD200 antibody (samalizumab) in patients with advanced stage B cell chronic lymphocytic leukemia (B-CLL) or multiple myeloma (MM). Blood 116: 2465, 2010.

40 A Multicenter, Dose-Escalation, Phase I Study of Samalizumab (ALXN6000) to Evaluate the Parmacokinetics, Safety, and Tolerability in Patients with Advanced Cancer. NCT02987504, www.ClinicalTrials.gov. Accessed 22 February 2018.

Received February 23, 2018

Revised March 15, 2018

Accepted March 22, 2018 